\title{
Research of Career Planning on the university Students of Network Engineering
}

\author{
$\operatorname{Min} \mathrm{Xu}^{1, \mathrm{a},{ }^{*}}$ \\ 'Zaozhuang University,Zaozhuang,Shandong,China \\ a170303726@qq.com \\ ${ }^{*}$ Corresponding author
}

Keywords: Network engineering, Career planning, Employment.

\begin{abstract}
At present, the demand for quantity and quality of China's network engineering professionals is increasing, In this case, how to realize students' successful employment and self-worth in the future really worth investigating. This paper explores the basis and satisfaction of college students' choosing of their major, as well as the cognitive status quo and behavior status of students' career planning, so as to lay foundations for students to develop scientific and rational career planning, thus improving the employability of students.
\end{abstract}

\section{基于网络工程专业大学生的职业生涯规划调查研究}

\author{
徐敏 $1, a,{ }^{*}$ \\ 1本庄学院信息科学与工程学院, 菄庄, 山东, 中国 \\ a170303726@qq.com \\ *通讯作者
}

关键词: 网络工程; 职业生涯规划;就业

中文摘要. 我国对网络工程专业的人才在数量和质量需求日益增加, 在这种情况下, 学生在未 来如何成功就业和实现自我价值值得研究。本文通过探索大学生选择本专业的依据及满意度, 职业生涯规划的认知现状及行为现状等。为学生制定科学合理的职业生涯规划奠定基础, 从 而提高学生就业能力。

\section{1. 引言}

高等教育已经成精英教育进入大众化教育阶段, 毕业人数持续上升, 供求关系结构性矛 盾突出等原因, 加重了大学生就业难的现象。同时, 随着信息技术的快速发展, 网络已在社 会各个领域中占据着举足轻重的位置, 为了满足网络方面人才需求, 我校从 2010 年开始招生 网络工程专业, 本专业的应用性较强, 从毕业生的就业去向来看, 多数的大学生都从事与本 专业相关的工作。在这种情况下，职业生涯规划成为社会的焦点。

大学生职业生涯规划是动态的过程, 影响人的整个生命历程, 指大学生结合自身情况和 外部工作世界, 为自己确立职业方向、职业目标, 为实现职业生涯目标而制定行动时间和方 案, 实现人生价值。 


\section{2. 网络工程专业大学生的职业生涯规划}

为了解网络工程学生对职业生涯规划的认知和行为现状，根据本专业情况和职业生涯规 划的内容, 设计并编制了大学生职业生涯规划的问卷, 采用随机抽样的方法, 选择被试 80 人, 共发放问卷 80 份，回收有效问卷为 78 份，大一 30 人，大二 23 人，大三 25 人，有效率为 $97 \%$ 。

\section{1 网络工程专业的选择依据及满意度}

网络工程专业是为了适应社会需求，促进信息化产业的发展而诞生的新专业。见表1，大 学生选择本专业主要依据他人建议, 从年级来看, 听从他人建议的主要是大一和大二的学生, 大三学生是个人的兴趣。由此可见, 多数大学生报考本专业时, 是听从父母或老师等他人的 建议, 而不是已自己的兴趣为出发点, 但通过三年的学习和生活, 大部分学生都能对本专业 产生一定的兴趣。虽然选择本专业主要是听从他人建议, 但大部分学生对本专业的满意度挺 高的。

表 1 选择网络工程专业的依据及满意度

\begin{tabular}{|c|c|c|c|c|c|c|c|c|c|}
\hline 项目 & $\begin{array}{c}\text { 个人 } \\
\text { 兴趣 }\end{array}$ & $\begin{array}{c}\text { 他人 } \\
\text { 建议 }\end{array}$ & $\begin{array}{c}\text { 职业 } \\
\text { 前景 }\end{array}$ & $\begin{array}{c}\text { 随意 } \\
\text { 选择 }\end{array}$ & $\begin{array}{c}\text { 很满 } \\
\text { 意 }\end{array}$ & 满意 & 中等 & $\begin{array}{c}\text { 不满 } \\
\text { 意 }\end{array}$ & $\begin{array}{c}\text { 很不满 } \\
\text { 意 }\end{array}$ \\
\hline 专业依据（大一） & $23 \%$ & $53 \%$ & $23 \%$ & & $10 \%$ & $53 \%$ & $33 \%$ & $3 \%$ & \\
\hline 专业依据（大二） & $4 \%$ & $52 \%$ & $44 \%$ & & $9 \%$ & $43 \%$ & $35 \%$ & $9 \%$ & \\
\hline 专业依据（大三） & $44 \%$ & $24 \%$ & $24 \%$ & $8 \%$ & $20 \%$ & $52 \%$ & $28 \%$ & & $4 \%$ \\
\hline 专业依据（总） & $24 \%$ & $44 \%$ & $29 \%$ & $3 \%$ & $13 \%$ & $50 \%$ & $32 \%$ & $4 \%$ & $1 \%$ \\
\hline
\end{tabular}

\section{2 网络工程大学生的职业生涯规划的认知现状}

$29 \%$ 的大学生认为职业生涯规划很重要, 56\%重要, 15\%的无所谓, 认为总体重视程度从 高到低分别为大一、大三和大二。本校在大一下学期开设职业生涯规划课程, 学生刚刚结束 本课程的学习, 大三在过一年就面临毕业, 因此, 大一和大三多数学生认为职业规划很重要。 其中大二学生 $48 \%$ 的认为无所谓, 多数学生仍没有重视, 造成的原因有待于进一步调查, 但 需要加强对他们进行生涯规划方面的教育, 这样有利于他们更好的发展和择业。

网络工程学生认为在自我、兴趣、性格、价值观和能力方面的认知有很清楚的了解, 见 表 2 , 无论从总体还是年级来看, 多数学生对自己有所了解, 能清晰的认识自己, 了解自己的 兴趣、优势和劣势, 这对今后的专业学习、择业和人生发展都非常有利, 但大二学生在这五 个方面的认识要明显的低于大一和大三学生, 跟他们认为职业生涯规划是无所谓的观念一致。

表2 网络工程学生对自我的认知

\begin{tabular}{|c|c|c|c|c|c|c|c|c|c|c|c|}
\hline 年级 & 项目 & 很了解 & 了解 & 不清楚 & 不了解 & 年级 & 项目 & 很了解 & 了解 & 不清楚 & $\begin{array}{l}\text { 不了 } \\
\text { 解 }\end{array}$ \\
\hline \multirow{5}{*}{ 大一 } & 自我 & $10 \%$ & $83 \%$ & $7 \%$ & & \multirow{5}{*}{ 大三 } & 自我 & $36 \%$ & $44 \%$ & $20 \%$ & \\
\hline & 兴趣 & $23 \%$ & $63 \%$ & $13 \%$ & & & 兴趣 & $40 \%$ & $44 \%$ & $16 \%$ & \\
\hline & 性格 & $17 \%$ & $77 \%$ & $7 \%$ & & & 性格 & $32 \%$ & $60 \%$ & $8 \%$ & \\
\hline & 价值观 & $23 \%$ & $67 \%$ & $10 \%$ & & & 价值观 & $32 \%$ & $52 \%$ & $16 \%$ & \\
\hline & 能力 & $13 \%$ & $70 \%$ & $17 \%$ & & & 能力 & $40 \%$ & $52 \%$ & $8 \%$ & \\
\hline \multirow{5}{*}{ 大二 } & 自我 & $26 \%$ & $39 \%$ & $22 \%$ & $13 \%$ & \multirow{5}{*}{ 总 } & 自我 & $23 \%$ & $62 \%$ & $12 \%$ & $3 \%$ \\
\hline & 兴趣 & $22 \%$ & $48 \%$ & $30 \%$ & & & 兴趣 & $28 \%$ & $53 \%$ & $19 \%$ & \\
\hline & 性格 & $17 \%$ & $57 \%$ & $13 \%$ & $13 \%$ & & 性格 & $22 \%$ & $65 \%$ & $9 \%$ & $4 \%$ \\
\hline & 价值观 & $30 \%$ & $39 \%$ & $26 \%$ & $4 \%$ & & 价值观 & $28 \%$ & $54 \%$ & $17 \%$ & $1 \%$ \\
\hline & 能力 & $22 \%$ & $57 \%$ & $17 \%$ & $4 \%$ & & 能力 & $24 \%$ & $60 \%$ & $14 \%$ & $1 \%$ \\
\hline
\end{tabular}


由此可见，学生已经充分意识到职业生涯规划的重要性，而且对自我探索的五个方面有 清晰的认识, 调查显示, 大部分学生认为职业生涯规划主要目的是确定未来奋斗目标（占 $54 \%$ ），完成老师布置的任务（24\%），找到适合自己的工作（21\%）。

\section{3 网络工程大学生的职业生涯规划的行为现状}

\subsection{1 网络工程专业的就业形势}

学生对本专业的就业形势的态度, 认为就业严峻占 $31 \%$, 就业中等占 $41 \%$, 就业情况不 清楚占 $19 \%$, 就业容易占 $9 \%$ 。从年级来看, 从大一到大三认为就业严峻的分别为 $(27 \%, 26 \%, 40 \%)$; 中等 $(63 \%, 35 \%, 20 \%)$; 不清楚 $(7 \%, 17 \%, 36 \%)$, 大三学生认为就业严 峻最多, 多数学生对就业形势处于平常心, 大一学生刚踏入大学, 对就业的问题持有一种积 极乐观的态度, 大三学生马上面临踏入社会, 感觉到就业压力, 认为找工作比较难, 找到一 份好工作更难。调查显示, $65 \%$ 的学生认为就业难是由供求关系不平衡造成, $64 \%$ 的认为是 自身能力不足, 39\%的认为缺乏职业规划或就业指导的相关知识, $26 \%$ 的认为是扩招。

2.3.2 网络工程学生对工作世界的认识

见表 3 , 学生对外部工作世界和用人单位的需求, 有所了解分别占 $47 \%$ 和 $38 \%$, 从年级看, 与他们对就业形势的认识是一致的, 大一学生持有一种乐观的态度, 个人认为学生这种认识 是有些盲目的, 而大三学生认为自己对外部世界和用人单位的需求都不是很清楚 (都占 $44 \%$ ), 这会影响毕业生的择业和发展, 因此, 要加强对大三学生就业指导。

表3 网络工程学生对工作世界的认识

\begin{tabular}{|c|c|c|c|c|c|c|c|c|c|}
\hline \multirow{2}{*}{ 年级 } & \multirow{2}{*}{ 项目 } & \multicolumn{2}{|c|}{ 很了解 } & \multicolumn{2}{|c|}{ 了解 } & \multicolumn{2}{|c|}{ 不清楚 } & \multicolumn{2}{c|}{ 不了解 } \\
\cline { 3 - 10 } & $\mathrm{n}$ & $\%$ & $\mathrm{n}$ & $\%$ & $\mathrm{n}$ & $\%$ & $\mathrm{n}$ & $\%$ \\
\hline \multirow{2}{*}{ 大一 } & 工作世界 & 4 & $13 \%$ & 18 & $60 \%$ & 7 & $23 \%$ & 1 & $3 \%$ \\
\cline { 2 - 11 } & 用人单位需求 & 4 & $13 \%$ & 13 & $43 \%$ & 11 & $37 \%$ & 2 & $7 \%$ \\
\hline \multirow{2}{*}{ 大二 } & 工作世界 & 7 & $30 \%$ & 9 & $39 \%$ & 7 & $30 \%$ & 0 & $0 \%$ \\
\cline { 2 - 11 } & 用人单位需求 & 6 & $26 \%$ & 9 & $39 \%$ & 7 & $30 \%$ & 1 & $4 \%$ \\
\hline \multirow{2}{*}{ 大三 } & 工作世界 & 4 & $16 \%$ & 10 & $40 \%$ & 11 & $44 \%$ & 0 & $0 \%$ \\
\cline { 2 - 11 } & 用人单位需求 & 5 & $20 \%$ & 8 & $32 \%$ & 11 & $44 \%$ & 1 & $4 \%$ \\
\hline \multirow{2}{*}{ 总 } & 工作世界 & 15 & $19 \%$ & 37 & $47 \%$ & 25 & $32 \%$ & 1 & $1 \%$ \\
\cline { 2 - 10 } & 用人单位需求 & 15 & $19 \%$ & 30 & $38 \%$ & 29 & $37 \%$ & 4 & $5 \%$ \\
\hline
\end{tabular}

\subsection{3 网络工程学生职业目标方面的认识}

见表 4, 33\%的学生有清晰的长期目标, 54\%的学生有明确的短期目标, 无长远目标, 只 有 $12 \%$ 和 $1 \%$ 的学生是目标模糊和没有目标, 大部分学生在校期间都有清晰具体的目标。

$36 \%$ 学生为自己的目标行动过, 而且还一直坚持着 $(37 \%, 17 \%, 40 \%), 51 \%$ 学生行动过, 但只坚持一段时间就停止了 $(53 \%, 61 \%, 52 \%), 13 \%$ 学生没有为目标付诸于行动。由此可见, 大部分学生为自己的目标行动努力过, 但因某些原因而放弃, 大二学生最明显, 因此, 要正 确的教育和引导大学生, 尤其对大二学生要多关注。59\%的学生认为职业目标的确定对在校 期间的学习有一定的影响, $28 \%$ 的学生认为影响有很大, $4 \%$ 的学生认为没有影响。因此, 要 尽早协助大学生制定合理的职业生涯规划。

表4 网络工程学生职业目标方面的认识

\begin{tabular}{|c|c|c|c|c|c|c|c|c|}
\hline \multirow{2}{*}{ 项目 } & \multicolumn{2}{|c|}{ 长期目标 } & \multicolumn{2}{|c|}{ 短期 } & \multicolumn{2}{c|}{ 目标模糊 } & \multicolumn{2}{c|}{ 没有目标 } \\
\cline { 2 - 9 } & $\mathrm{n}$ & $\%$ & $\mathrm{n}$ & $\%$ & $\mathrm{n}$ & $\%$ & $\mathrm{n}$ & $\%$ \\
\hline 职业目标 (大一) & 7 & $23 \%$ & 17 & $57 \%$ & 5 & $17 \%$ & 1 & $3 \%$ \\
\hline 职业目标 (大二) & 9 & $39 \%$ & 11 & $48 \%$ & 3 & $13 \%$ & & \\
\hline 职业目标 (大三) & 10 & $40 \%$ & 14 & $56 \%$ & 1 & $4 \%$ & & \\
\hline 职业目标 (总) & 26 & $33 \%$ & 42 & $54 \%$ & 9 & $12 \%$ & 1 & $1 \%$ \\
\hline
\end{tabular}




\subsection{4 网络工程学生的职业定位的现状}

调查显示, 本专业学生确定职业目标后, 69\%的学生认为会促进学习的积极主动性, 59\% 的学生对未来充满希望, $55 \%$ 的学生奋斗目标更加明确, $5 \%$ 的学生认为没有影响, 职业目标 的确立为后续成功奠定了基础。本专业学生在未来择业中, 学生最看重的从高到低分别是工 作的稳定性（64\%）、自由（47\%）、收入（45\%）、发展空间（40\%）、企业文化（14\%）, 工作的稳定性和自由仍是现代大学生的追求。

学生的择业标准各不相同, 择业标准从高到低分别为职业前景 $(68 \%)$ 、个人兴趣 $(60 \%)$ 、 父母的要求 $(44 \%)$ 、职业待遇 $(39 \%)$ 、职业的发展空间 $(36 \%)$ ，学生在择业时最看重的 还是职业前景, 说明学生能够考虑到长远的发展, 比较有远见, 不被眼前的优势有吸引, 在 择业中以个人兴趣为出发点, 兴趣是快乐的源泉, 是职业最初的原动力, 有利于学生未来的 职业发展。

\subsection{5 职业生涯规划的影响因素}

当我们在进行职业生涯规划时, 往往会多方面考虑。调查显示, $77 \%$ 的学生认为受个人 因素的影响, 如自身的能力, 兴趣, 性格等因素, 63\%的学生认为是受家庭因素的影响, 主 要指父母的建议, 家庭经济情况等, 48\%受专业因素的影响, 45\%受社会因素的影响, 23\%的 认为受国家政策的影响。

\section{3. 讨论与建议}

通过调查研究表明, 学生选择本专业的依据是他人建议, 对专业的满意度持有乐观的态 度, 对专业的满意度是职业生涯规划中的重要部分之一。学生充分意识到职业生涯规划的重 要性, 也对自我探索 (兴趣、性格、价值观、能力) 有正确的认知, 大二的学生有点偏低, 要积极关注, 主动引导, 培养他们的职业意识, 加强对自我的认识。

本专业学生对就业形势持有一种平常心的心态, 能够正确看待就业问题。在对外部工作 环境和用人单位需求方面, 虽然有所了解, 但不清晰, 要加强这方面的教育, 只有对外部越 了解越有助于学生的发展和就业。大部分学生都有短期的职业目标, 在付诸于行动时, 执行 力有些薄弱, 因此, 协助他们制定科学的职业生涯目标, 提高实际行动比例。在职业定位方

向, 大部分学生都能从自身和外部现实为出发点考虑，树立正确的职业定位和择业观念。

建立完善的职业生涯规划体制, 协助本专业学生及时制定科学的职业生涯规划, 有助于 提高学生的学习态度、综合素质、明确方向和提高就业能力, 实现顺利就业和人生价值。

\section{References}

[1] Lanmei Ban, Career Planning and Its Influential Factor of College Students, China Journal of Health Psychology, 21(3) ,pp.460-462,2013.

[2] Hong-he LI, The Study of the Medical Students' Cognition, Attitude and Behavior of the Career Planning, Journal of China Medical University,43(2), pp.1138-141,2014.

[3] Jianxin He, Innovation and practice of the training system of network engineers, Computer Era, 4,pp. 60-62, 2012. 